\title{
The American Association of Clinical Endocrinologists/American College of Endocrinology (AACE/ACE) algorithm for managing glycaemia in patients with type 2 diabetes mellitus: comparison with the ADA/EASD algorithm
}

\author{
H. W. Rodbard • P. S. Jellinger
}

Received: 11 August 2010 /Accepted: 11 August 2010/Published online: 12 September 2010

(C) Springer-Verlag 2010

Keywords American Association of Clinical Endocrinologists/American College of Endocrinology (AACE/ACE) algorithm · American Diabetes Association/European Association for the Study of Diabetes (ADA/EASD) algorithm · Biguanides · Dipeptidyl peptidase 4 (DPP-4) inhibitors · Evidence-based guidelines · Glucagon-like peptide 1 (GLP-1) analogues · Pharmacotherapy $\cdot$ Sulfonylureas · Type 2 diabetes mellitus

\author{
Abbreviations \\ AACE American Association of Clinical Endocrinologists \\ ACE American College of Endocrinologists \\ DPP-4 Dipeptidyl peptidase 4 \\ GLP-1 Glucagon-like peptide 1
}

The authors were co-chairpersons of the committee that developed the AACE/ACE Algorithm for Management of Patients with Diabetes. Both had served previously on the committee that developed the AACE Diabetes Guidelines, and both have previously served as President of both the AACE and the ACE

H. W. Rodbard $(\bowtie)$

Endocrine and Metabolic Consultants,

Suite 250, 3200 Tower Oaks Blvd,

Rockville, MD 20852, USA

e-mail: hrodbard@comcast.net

P. S. Jellinger

Division of Endocrinology, Diabetes and Metabolism,

University of Miami,

Miami, FL, USA
To the Editor: Schernthaner et al. [1] and Nolan [2] describe several serious limitations of the ADA/EASD algorithm for the management of type 2 diabetes [3]. Unfortunately, they did not provide an alternative algorithm. Nolan [2] implies that therapy must be individualised to the extent that a general algorithm may not be needed or desired, but he provides no practical guide.

The American Association of Clinical Endocrinologists (AACE) and the American College of Endocrinology (ACE) recently published a new algorithm for the management of patients with type 2 diabetes [4]. This algorithm was developed by a panel of 14 clinical endocrinologists with extensive experience, who provide ongoing care to patients with type 2 diabetes. The AACE/ACE algorithm was also motivated by serious concerns regarding the limitations of the ADA/EASD algorithm. We would like to point out some of the most important differences between the AACE/ACE and the ADA/EASD algorithms.

1. The ADA/EASD algorithm [3] considers as first tier only four regimens involving four classes of medications: metformin, metformin + sulfonylurea, metformin + basal insulin, and metformin + intensive insulin. It considers three more regimens as second tier: metformin + thiazolidinedione (pioglitazone), metformin + glucagonlike peptide 1 (GLP-1) receptor agonist, and metformin + pioglitazone + sulfonylurea. In contrast, the AACE/ACE algorithm [4] includes nine classes of medications: biguanides, GLP-1 receptor agonists, dipeptidyl peptidase 4 (DPP-4) inhibitors, several types of insulin therapy (basal, prandial, biphasic, multiple daily injections or basal bolus), thiazolidinediones, sulfonylureas, glinides, $\alpha$-glucosidase inhibitors and colesevelam. 
These are considered in more than 20 combinations of mono-, dual, and triple therapy, and additional combinations of insulin therapy with other agents are also included.

2. The AACE/ACE algorithm [4] emphasises safety and efficacy rather than medication cost and years of commercial availability of medications [3].

3. The AACE/ACE algorithm [4] emphasises the total cost of care rather than the cost of medications per se. For example, minimising the risk of hypoglycaemia and its associated hospital visits, minimising weight gain, and minimising complications are associated with significant cost savings.

4. The AACE/ACE algorithm [4] places increased emphasis on incretin-based therapies, including DPP-4 inhibitors and GLP-1 agonists, in view of their efficacy, safety (markedly reduced risk of hypoglycaemia), and associated weight loss (with GLP-1 agonists) or lack of significant effect on weight (DPP-4 inhibitors). The ADA/EASD algorithm [3] reflected concerns that these agents are new and relatively untested. Such arguments are no longer tenable: both exenatide and sitagliptin have been available and prescribed extensively for several years, with millions of patients receiving these medications.

5. The AACE/ACE algorithm [4] places a much lower priority on the use of sulfonylureas. Although sulfonylureas are inexpensive and have been available for decades, they are associated with significant risks of hypoglycaemia (especially in the elderly) and weight gain, and are effective for only a short period of time, as clearly demonstrated in the UK Prospective Diabetes Study (UKPDS).

6. The AACE/ACE algorithm places a lower priority for use of thiazolidinediones because of the frequent adverse events of weight gain, fluid retention, increased risk of congestive heart failure and elevated risk of fractures in both men and women, including premenopausal women [4]

7. The $\mathrm{HbA}_{1 \mathrm{c}}$ goal must be individualised, especially for patients with hypoglycaemia, hypoglycaemia unawareness, or patients with long duration of diabetes and established coronary artery disease.

8. Choice of therapy in the AACE/ACE algorithm is stratified by $\mathrm{HbA}_{1 \mathrm{c}}$ depending on the degree of hyperglycaemia when the patient presents for therapy. (1) If the initial $\mathrm{HbA}_{1 \mathrm{c}}$ is $<7.5 \%$, then monotherapy may be sufficient to achieve a goal of $6.5 \%$. Metformin is the preferred agent in the absence of contraindications and if well tolerated. Several other options are provided, including the use of the GLP-1 agonist exenatide. (2) If the initial $\mathrm{HbA}_{1 \mathrm{c}}$ is between $7.6 \%$ and $9.0 \%$, the $\mathrm{AACE} / \mathrm{ACE}$ algorithm recommends moving directly to dual therapy, since it is highly unlikely that any monotherapy could achieve the goal of $6.5 \%$. The highest priority is placed on combinations of metformin and incretin-based therapies, with a preference for GLP-1 agonists in view of their greater efficacy. (Following the initial publication of the AACE algorithm, exenatide was approved for monotherapy in addition to its previous approval for combination therapy, and liraglutide was approved for combination therapy.) For patients with $\mathrm{HbA}_{1 \mathrm{c}}$ levels between 7.6\% and $9.0 \%$, sulfonylureas are given greater priority than glinides in view of their greater efficacy and lower risk for hypoglycaemia, and colesevelam and $\alpha$-glucosidase inhibitors were not recommended in view of their lower efficacy. (3) For patients with $\mathrm{HbA}_{1 \mathrm{c}}$ levels above $9.0 \%$, the AACE/ACE algorithm recommends initiating treatment with dual or triple therapy. The algorithm recommends moving directly to insulin therapy if the patient failed to achieve his/her target $\mathrm{HbA}_{1 \mathrm{c}}$ level on previous pharmacotherapy or is symptomatic because of hyperglycaemia. In all regimens it is essential to monitor therapy closely at 2 to 3 month intervals. If the patient has not achieved the desired goals for glycaemic control, therapy should be advanced - either by increasing dosage or by change of regimen.

The AACE/ACE review of the risks and benefits of various classes of medications (see Table 1 in [4]) and considerations for selection of therapy is remarkably similar to that of Schernthaner et al. [1]. However, the AACE/ACE algorithm, available at www.aace.com/pub (accessed 28 August 2010), provides a flowchart or 'treatment path' (see Fig. 1 in [4]) that is simple, clear, and provides meaningful priorities and guidance to the user [4]. It also provides more specific guidance than some alternatives $[3,5,6]$.

Schernthaner et al. [1] and Nolan [2] argue that algorithms should be evidence based. This would be desirable in principle but has not been attained in practice. Guidelines, such as the AACE guidelines [7] and ADA guidelines [8], should be evidence based to the extent that sufficient, consistent evidence is available, with careful documentation of levels of evidence. Unfortunately, this inevitably results in a large document that is not likely to be sufficiently user friendly for quick reference by the physician at the point of care, which is perhaps one of the reasons that guidelines are rarely used at the point of care. In contrast, an algorithm [3-6] can be short, simple and focused, and does not necessarily need to display, evaluate and cross-reference the evidence. Algorithms [3-6] should be based on guidelines $[7,8]$ to the extent possible, and synthesised by a consensus of experts with extensive and appropriate clinical experience. 
Duality of interest $H$. W. Rodbard has received consultant honoraria from Abbott Laboratories, AstraZeneca Pharmaceuticals, Biodel, GlaxoSmithKline, MannKind Corporation, Merck \& Co, Novo Nordisk, sanofi-aventis US and Takeda Pharmaceuticals America; speaker honoraria from Amylin Pharmaceuticals, AstraZeneca Pharmaceuticals, Bristol-Myers Squibb Company, GlaxoSmithKline, Eli Lilly and Company, Merck \& Co, Novo Nordisk and sanofi-aventis US; and research grant support from Biodel, MacroGenics, Novo Nordisk, and sanofi-aventis US. P. S. Jellinger has received speaker honoraria from Amylin Pharmaceuticals, Eli Lilly and Company, Merck \& Co, Novo Nordisk, sanofi-aventis US and Takeda Pharmaceuticals; and consultant honoraria from Daiichi Sankyo, MannKind Corporation and Tethys Bioscience.

\section{References}

1. Schernthaner G, Barnett AH, Betteridge DJ et al (2010) Is the ADA/EASD algorithm for the management of type 2 diabetes (January 2009) based on evidence or opinion? A critical analysis. Diabetologia 53:1258-1269

2. Nolan JJ (2010) Consensus guidelines, algorithms and care of the individual patient with type 2 diabetes. Diabetologia 53:1247-1249; erratum 53:2078

3. Nathan DM, Buse JB et al (2009) American Diabetes Association; European Association for Study of Diabetes. Medical management of hyperglycemia in type 2 diabetes mellitus: a consensus algorithm for the initiation and adjustment of therapy: a consensus statement of the American Diabetes Association and the European Association for the Study of Diabetes. Diabetologia 52:17-30

4. Rodbard HW, Jellinger PS, Davidson JA et al (2009) Statement by an American Association of Clinical Endocrinologists/American College of Endocrinology consensus panel on type 2 diabetes mellitus: an algorithm for glycemic control. Endocr Pract 15:540-559, erratum in 15:768-770 (the updated/corrected version is available from www.aace.com/pub/pdf/GlycemicControlAlgorithm.pdf, accessed 28 August 2010)

5. Inzucchi SE (2010) Diabetes facts and guidelines, 2010-2011. Yale Diabetes Center, New Haven, pp 71-79. Available from http:// medicine.yale.edu/intmed/endocrin/Images/695 21366 Takeda Yale_KLL_tcm314-50135.PDF, accessed 28 August 2010

6. Woo V (2009) Important differences: Canadian Diabetes Association 2008 clinical practice guidelines and the consensus statement of the American Diabetes Association and the European Association for the Study of Diabetes. Diabetologia 52:552-553, author reply $554-555$

7. Rodbard HW, Blonde L, Braithwaite SS et al (2007) AACE Diabetes Mellitus Clinical Practice Guidelines Task Force. American Association of Clinical Endocrinologists medical guidelines for clinical practice for the management of diabetes mellitus. Endocr Pract 13 (Suppl 1):1-68, Available from www.aace.com/pub/pdf/guidelines/ DMGuidelines2007.pdf, accessed 28 August 2010

8. American Diabetes Association (2010) Standards of medical care in diabetes-2010. Diabetes Care 33(Suppl 1):S11-S61, Available from http://care.diabetesjournals.org/content/33/Supplement_1/S11. full.pdf + html, accessed 28 August 2010 